\title{
The effects of changeover delays of fixed or variable duration on concurrent variable-interval performance in pigeons
}

\author{
FRANS van HAAREN \\ Western Michigan University, Kalamazoo, Michigan 49001
}

\begin{abstract}
The effects of changeover delays of fixed or variable duration on concurrent variable-interval performance in pigeons were investigated in a series of three experiments. Experiment $1 \mathrm{com}$ pared the effects of a fixed, variable, or variable signaled changeover delay on interchangeover times and responding during and after the changeover delay. The duration of the changeover delays was systematically varied in Experiment 2, and the relative reinforcement frequencies were manipulated in Experiment 3. Interchangeover times were found to be shorter when changeover delays of variable duration were compared with those of fixed duration. Changeover delays of fixed duration produced higher response rates during the changeover delay than after the changeover delay had elapsed; changeover delays of variable duration produced such differences to a lesser extent. It was concluded that the changeover delay in concurrent variableinterval schedules of reinforcement functionally acts as a delay period to the next opportunity for reinforcement, possibly serving as a conditioned reinforcer for the behavior preceding it (the interchangeover time) and as a discriminative stimulus for the behavior in its presence (response rates during the delay).
\end{abstract}

Two different methods of programming concurrent schedules of reinforcement have been widely used. In one of these (Findley, 1958), responding is maintained on one (main) key, while the subject switches schedules by responding on a second (changeover) key; each schedule on the main key is associated with its own discriminative stimulus. In the other method (Herrnstein, 1961), responding is maintained on two separate response manipulanda, each associated with its own schedule of reinforcement. Matching between relative reinforcement variables and relative performance measures has been demonstrated extensively with both kinds of procedures (DeVilliers, 1977).

It has been found that a changeover delay (COD) is necessary if matching is to be obtained. A COD specifies a minimum amount of time that has to elapse between a changeover $(\mathrm{CO})$ response and a subsequently reinforced response. The presence of a COD effectively eliminates the possibility of immediately reinforcing response sequences that include a $\mathrm{CO}$ response (Catania, 1966).

Several factors affect the number of $\mathrm{CO}$ responses

The author would like to thank M. Kay Malott, who kindly provided the laboratory equipment used in this experiment. David $O$. Lyon, Alan Poling, and Jack Michael offered critical suggestions on earlier versions of this manuscript. Kathleen M. Krafft assisted with the data collection. Special thanks are extended to Karen Tyson for helping to prepare the manuscript. Reprint requests should be directed to Frans van Haaren, Department of Psychology, Tilburg University, Hogeschoollaan 225, 5000 LE Tilburg, The Netherlands. between schedule components. Increases in the duration of the COD result in a decrease in the number of CO responses (Allison \& Lloyd, 1971; Brownstein \& Pliskoff, 1968; Shull \& Pliskoff, 1967). An increase in shock intensity or in the duration of a time-out period following a $\mathrm{CO}$ response has similar effects (Todorov, 1971), as does an increase in a fixed-ratio (FR) requirement scheduled on the CO key (Stubbs \& Pliskoff, 1969; White, 1979). The number of CO responses varies also as a function of the difference in reinforcement frequency between the two components of the schedule. The highest number of $\mathrm{CO}$ responses is observed when the reinforcement frequencies are equal in both components of the schedule (DeVilliers, 1977).

It appears that a COD of fixed duration has effects other than merely insuring the nonreinforcement of switching behavior. Pliskoff (1971) and Silberberg and Fantino (1970) measured response rates both during the COD and after the COD had elapsed. Both investigators reported consistently higher response rates during the COD period than after the COD had expired. Similar results were reported by Bourland and Miller (1978) and Killeen (1972). On the other hand, Guilkey, Shull, and Brownstein (1975) and White (1979) failed to observe this rate difference when they used a FR changeover requirement. Pliskoff, Cicerone, and Nelson (1978) reported results congruent with those of White and Guilkey et al.

The COD is a rather important procedural characteristic of concurrent schedules of reinforcement, and the following series of experiments was designed 
to further investigate its role in such procedures. The effects of CODs of fixed duration were compared with the effects of CODs of variable durations in three experiments in which COD responding, postCOD responding, interchangeover times, and relative response rate and time allocation measures were the major dependent variables of interest.

\section{EXPERIMENT 1}

In this experiment, the effects of a COD of fixed, variable, and variable but signaled duration were investigated on a concurrent variable-interval $90-\mathrm{sec}$ variable-interval 90 -sec (conc VI 90 VI 90 ) schedule of reinforcement.

\section{Method}

\section{Subjects}

Four 7-year-old White Carneaux pigeons served as subjects. All had been previously exposed to simple schedules of reinforcement. They were maintained at about $80 \%$ of their free-feeding weights by limiting access to pigeon grain. Water and grit were always available in the home cages.

\section{Apparatus}

Two Lehigh Valley, two-key pigeon testing chambers were used. The response keys $(2.5 \mathrm{~cm}$ in diameter) were located $23 \mathrm{~cm}$ from the floor of the chamber and $8.8 \mathrm{~cm}$ from either edge of the intelligence panel. The left key (main key) could be illuminated by a red or a green keylight; the right key (CO key) had a white vertical bar on a black background. The keys required a force in excess of .15 $\mathrm{N}$ to be operated. The stimuli were projected on the key through one-plane readout projectors (Industrial Electronics, Inc.). Access to grain was provided through a $5 \times 6 \mathrm{~cm}$ aperture located in the middle of the intelligence panel $11 \mathrm{~cm}$ above the floor of the chamber. Ventilation and a low level of masking noise were provided by an exhaust fan located on the outside of the chamber.

The experiment and data acquisition procedures were controlled by a PDP-8/F minicomputer (Digital Equipment Corporation) located in an adjacent room. The experimental chambers were connected to the computer through an interface provided by State Systems, Inc., of Kalamazoo. SUPERSKED software (Snapper, van Haaren, \& Inglis, 1978) was used to program the experimental events and data acquisition procedures.

\section{Procedures}

Baseline. A conc VI 90-sec VI 90-sec schedule of reinforcement was in effect during baseline training. A procedure similar to the one described by Findley (1958) was used to arrange the concurrent schedules. The interreinforcement intervals (constant probability) for both components of the schedule were derived from a formula devised by Catania and Reynolds (1968). The specific interreinforcement intervals were selected randomly from a list of
15 intervals. The timers for both components ran continuously except when reinforcement had been set up. In that case, the timer for the component in which reinforcement was available stopped until the scheduled reinforcer had been delivered. In addition, both timers were stopped during reinforcement delivery in either component. Duration of food presentation was $3 \mathrm{sec}$. A COD was not employed during baseline conditions; a response on the main key preceded by one on the $\mathrm{CO}$ key could be immediately reinforced. All sessions ended after $\mathbf{4 0}$ food presentations.

Experimental paradigm. All subjects were exposed to all experimental conditions; the order of exposure was different for groups of two pigeons. Conditions were changed when the data appeared stable and consistent trends were not present. Table 1 shows the sequence of conditions to which each subject was exposed and the number of sessions that each condition was in effect. The different conditions of the experiment are described below.

Fixed COD. A COD of fixed duration $(3 \mathrm{sec})$ was in effect following every response on the $\mathrm{CO}$ key. All other manipulations were identical to those of the baseline conditions.

Variable COD. A COD of variable duration, with an arithmetic mean of $3 \mathrm{sec}$, was introduced following a response on the $\mathrm{CO}$ key. The duration of any specific COD was determined by a probability gate that sampled every $.10 \mathrm{sec}$ with a .03 probability. All other manipulations were identical to those of the baseline conditions.

Variable signaled COD. A COD of variable duration (mean $3 \mathrm{sec}$ ) was introduced following a $\mathrm{CO}$ response. A horizontal white bar was superimposed on the color of the main key for the duration of the COD. All other manipulations were identical to those of the baseline conditions.

\section{Results}

Data presented are averaged across the last five sessions in each condition. Interchangeover times (ICT) are presented in Figure 1. The ICT is defined as the period of time that elapses between a $\mathrm{CO}$ response to one component of the schedule and a subsequent $\mathrm{CO}$ response to the other component. The shortest mean ICT was recorded for all subjects during baseline conditions in which a COD was not used. The longest mean ICT was recorded for three subjects when the COD of fixed duration was introduced, while the COD of variable duration with an added exteroceptive stimulus during the delay produced the shortest ICT of those conditions in which a COD was used, for three of the four subjects.

Figure 2 shows COD and post-COD response rates. COD response rates were higher than postCOD response rates for all subjects. The rate during the COD of fixed duration was higher than the rate

Table 1

Sequence of Conditions and Number of Sessions in Each Condition in Experiment 1

\begin{tabular}{|c|c|c|c|c|c|}
\hline \multirow[b]{2}{*}{ Condition } & \multicolumn{2}{|c|}{ Subject } & \multirow[b]{2}{*}{ Condition } & \multicolumn{2}{|c|}{ Subject } \\
\hline & 8178 & 8251 & & 8166 & 6274 \\
\hline Baseline & 36 & 36 & Baseline & 36 & 36 \\
\hline $\mathrm{COD}$ & & & COD & & \\
\hline Fixed & 25 & 25 & Variable & 24 & 24 \\
\hline Variable & 31 & 30 & Variable Signaled & 30 & 30 \\
\hline Variable Signaled & 19 & 20 & Fixed & 24 & 24 \\
\hline
\end{tabular}




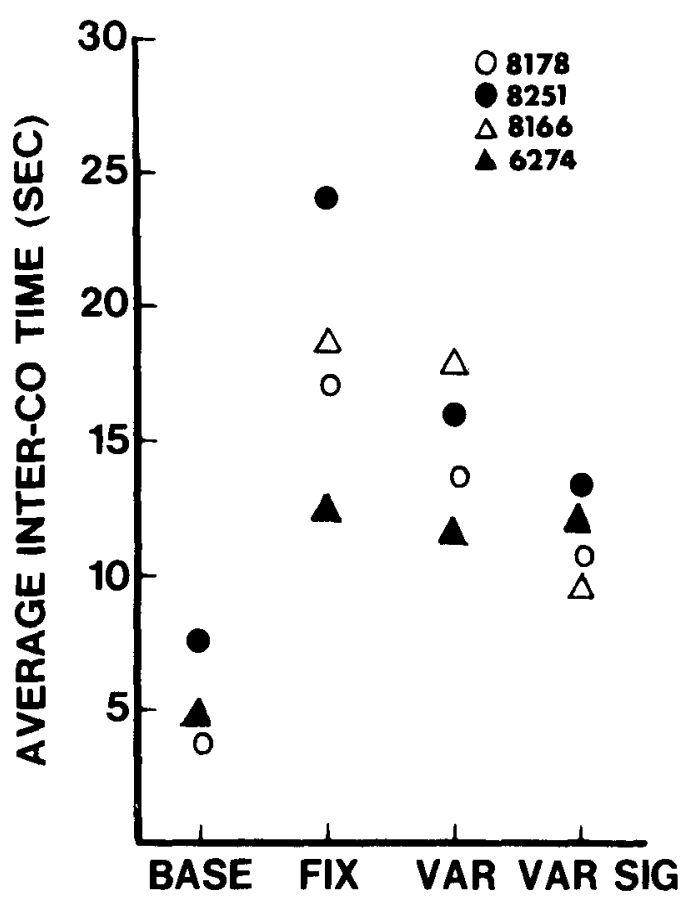

Figure 1. Average interchangeover times in Experiment 1.

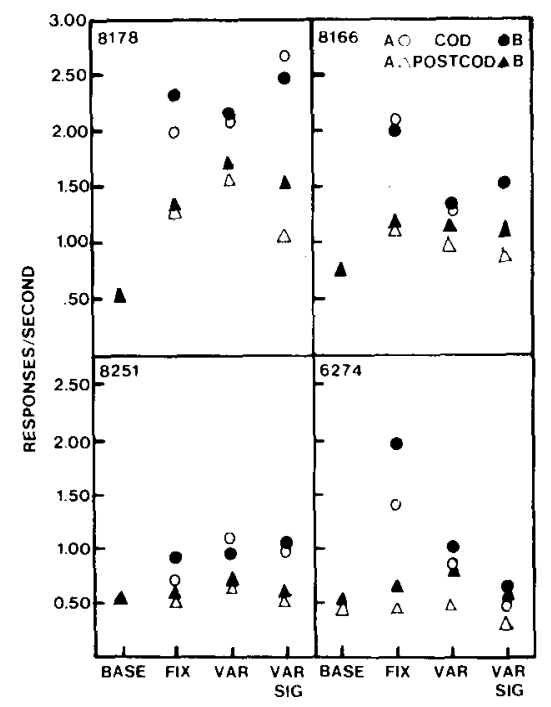

Figure 2. Average response rates (responses/second) during the changeover delay (circles) and post-COD periods (triangles) in Experiment 1. The letters $A$ and $B$ refer here and in all other figures to the two different schedule components.

during the other two CODs for two of the four subjects. No consistent trends could be observed across conditions in post-COD response rates.

\section{EXPERIMENT 2}

The data of Experiment 1 suggest that a COD of fixed duration can possibly have effects on behavior maintained by a concurrent variable-interval sched- ule that are quantitatively different from those of a COD of variable duration. This hypothesis was further investigated in Experiment 2, in which the duration of both the fixed and variable COD were systematically varied.

\section{Method}

\section{Subjects}

Two 7-year-old White Carneaux pigeons were used. One of them (8178) had served in Experiment 1 and the other (8875) had participated in other experiments involving simple and concurrent schedules of reinforcement. The subjects were maintained at about $80 \%$ of their free-feeding weights during the experiment. Water and grit were always available in the home cages.

\section{Apparatus \\ The apparatus used in this experiment was the same as that used in Experiment 1. \\ Procedure \\ No preliminary training was necessary, since both subjects had had previous experience with concurrent schedules of reinforce- ment.}

The duration of the CODs was systematically varied across different conditions in the experiment for individual subjects, although some data points were replicated between subjects. Subject 8178 was exposed to all CODs of fixed duration $(1,3,9$, and $15 \mathrm{sec}$ ) and two of variable duration (1 and $9 \mathrm{sec}$ ). Subject 8875 was exposed to all CODs of variable duration $(1,3,9$, and $15 \mathrm{sec}$ on the average) and two of fixed duration ( 1 and $9 \mathrm{sec}$ ). The COD of variable duration was determined by a probability gate that sampled every $.10 \mathrm{sec}$ with a probability appropriate to the average COD required. Table 2 provides an overview of all experimental conditions, the sequence in which they were presented, and the number of sessions that each subject was exposed to each condition. Conditions were changed when the data appeared stable for at least five sessions and no consistent trends were apparent.

\section{Results}

All data are based on the average of the last five sessions in each condition. Average ICTs are presented in Figure 3. The average ICT was a function of the duration of the COD whether it was of fixed

Table 2

Sequence of Conditions and Number of Sessions in Each Condition in Experiments 2 and 3

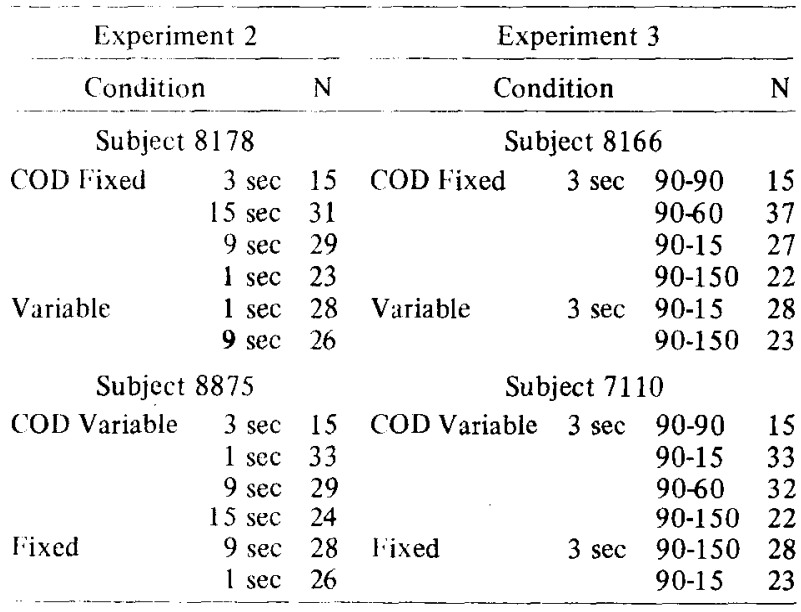




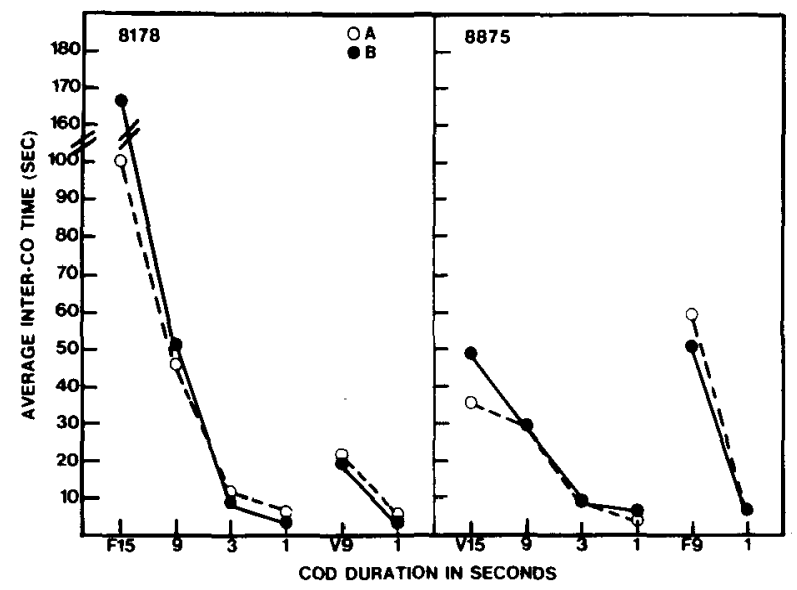

Figure 3. Average interchangeover times during the different conditions of Experiment 2. The symbols $F$ and $V$ on the abscissa indicate whether the changeover delay was of fixed or variable duration.

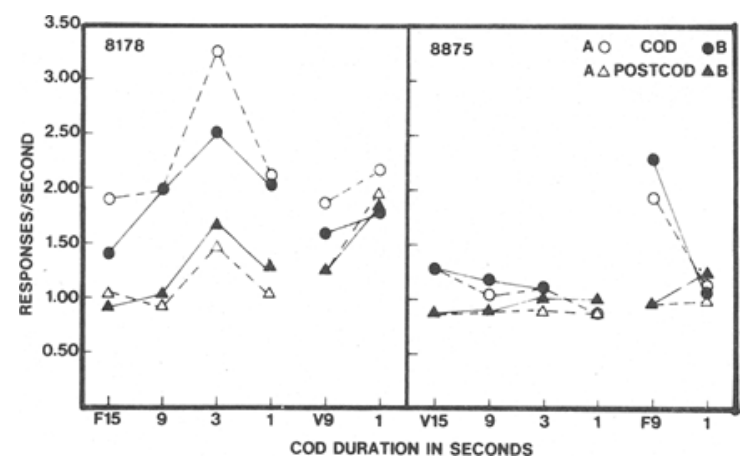

Figure 4. Average response rates (responses/second) during the COD (circles) and post-COD periods (triangles) in Experiment 2. The symbols $F$ and $V$ on the abscissa indicate whether the COD was of fixed or variable duration.

or variable duration: the longer the duration of the COD, the longer the ICT. However, the absolute ICT was longer for the COD of fixed duration than it was for the COD of variable duration.

Figure 4 shows COD and post-COD response rates during all conditions of the experiment. The COD of fixed duration resulted in higher response rates during the COD than after the COD had elapsed. No systematic relation was detected between the duration of the COD and the COD and post-COD response rates. There was a small difference between COD and post-COD response rates when a COD of variable duration was used. Both $C O D$ and postCOD response rates were approximately equal at all values of the COD of variable duration. The introduction of a COD of fixed duration of $9 \mathrm{sec}$ caused a separation of COD and post-COD rates for Sub- ject 8875 , while the introduction of the CODs of variable duration produced less of a difference between COD and post-COD rates for Subject 8178 .

\section{EXPERIMENT 3}

Experiment 2 showed that increasing the duration of a COD of fixed duration has effects on behavior maintained by concurrent VI-schedules of reinforcement that are quantitatively different from those obtained by increasing the duration of a COD of variable duration. The effects of a COD are dependent not only on the specific characteristics of the COD itself, but also on the difference in reinforcement frequencies between the two schedule components. It was the purpose of Experiment 3 to determine whether or not differential COD effects could be obtained when a COD of fixed or variable duration was held constant and the relative frequenicy of reinforcement in the different schedule components was varied.

\section{Method}

\section{Subjects}

Two 7-year-old White Carneaux pigeons were used. One of them (8166) had served in Experiment 1, and the other (7110) had participated in other experiments involving simple and concurrent schedules of reinforcement. The subjects were maintained at about $80 \%$ of their free-feeding weights. Water and grit were always available in the home cages.

\section{Apparatus}

The apparatus used in this experiment was the same as that used in Experiment 1.

\section{Procedure}

Preliminary training was not necessary, since both subjects had been previously exposed to concurrent schedules of reinforcement. They were exposed to a series of concurrent VI schedules in which the interreinforcement interval in one component was held constant at $90 \mathrm{sec}$ (component $\mathrm{A}$ ) and varied in the other component (component B). The interreinforcement interval in this component varied between experimental conditions and had values of 150,90 , 60 , and $15 \mathrm{sec}$. For one subject (8166), the COD was of fixed duration $(3 \mathrm{sec})$ at all relative reinforcement frequencies. For the other subject $(7110)$, the COD was of variable duration (average $3 \mathrm{sec}$ ). Two points of the relative reinforcement frequency continuum ( 150 and $15 \mathrm{sec}$ ) were replicated between subjects with the CODs interchanged. Table 2 gives an overview of the exact sequence of experimental conditions for each subject and the number of sessions that each condition was in effect. Conditions were changed when the data appeared stable for at least five consecutive sessions and no consistent trends were apparent.

\section{Results}

All data presented are based on the average of the last five sessions in each condition. Figure 5 shows the average ICT in the different experimental conditions. As can be seen, the mean ICT for both components changed in a systematic fashion as a function of manipulations in relative reinforcement frequen- 


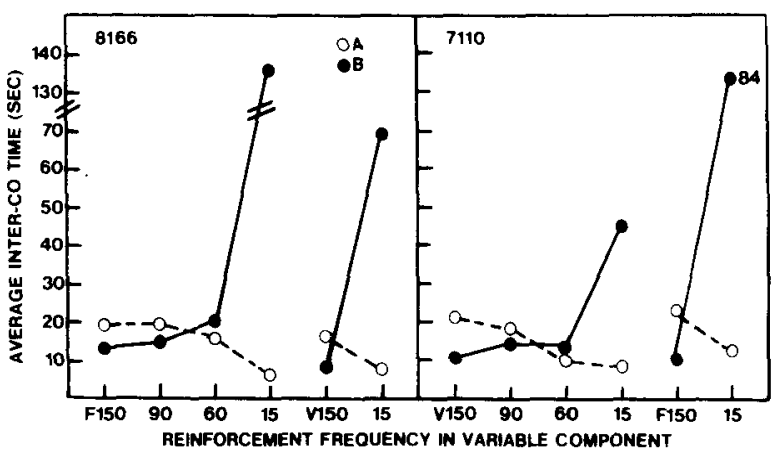

Figure 5. Average interchangeover times during the different conditions of Experiment 3. The symbols $F$ and $V$ on the abscissa indicate whether the COD was of fixed or variable duration. Values along the abscissa are average interreinforcement times (in seconds) arranged in increasing orders of reinforcement frequency.

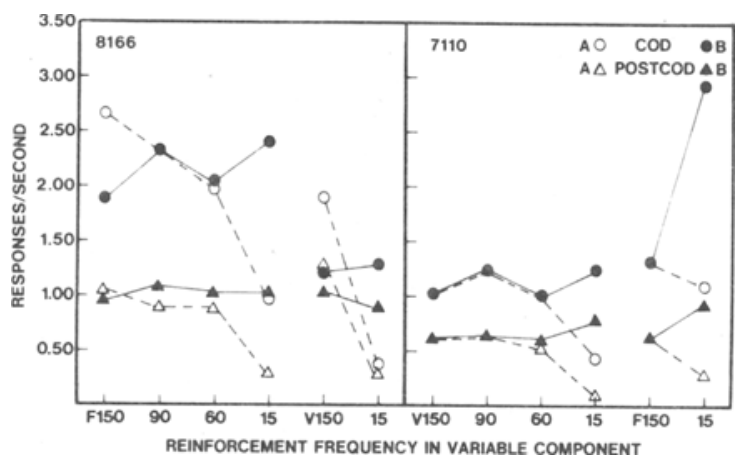

Figure 6. Average response rates (responses/second) during the COD (circles) and post-COD (triangles) periods in Experiment 3. The symbols $F$ and $V$ on the abscissa indicate whether the COD was of fixed or variable duration. Values along the abscissa are average interreinforcement times (in seconds) arranged in increasing orders of reinforcement frequency. cies. A relative increase in reinforcement frequency in component B produced an increase in the duration of the mean ICT for that component. The increase in ICT duration was less when a COD of variable duration was used than when a COD of fixed duration was in effect.

COD and post-COD response rates are depicted in Figure 6. The difference between COD and postCOD response rates was greater when a COD of fixed duration was in effect than when a COD of variable duration was used. Response rates in the unchanged component varied as a function of the reinforcement frequency in the variable component both post-COD and during the COD.

Figure 7 shows relative response rates and relative time allocation measures for both subjects. A distinction is made between COD and post-COD measures. As can be seen, response rate and time allocation measures reflected changes in relative reinforcement frequencies only for post-COD measures. The COD measures were insensitive to changes in reinforcement frequencies and did not match at all.

\section{GENERAL DISCUSSION}

Many of the data collected in this series of experiments confirm those reported by other investigators. ICTs between schedule components increased with increases in the duration of the COD, a finding previously reported by Allison and Lloyd (1971) and Shull and Pliskoff (1967), among others. Response rates during the COD of fixed duration were higher than post-COD rates, as anticipated on the basis of data collected by Silberberg and Fantino (1970), who first measured these responses separately.

The present series of experiments also produced a number of new findings. First, it was found that the
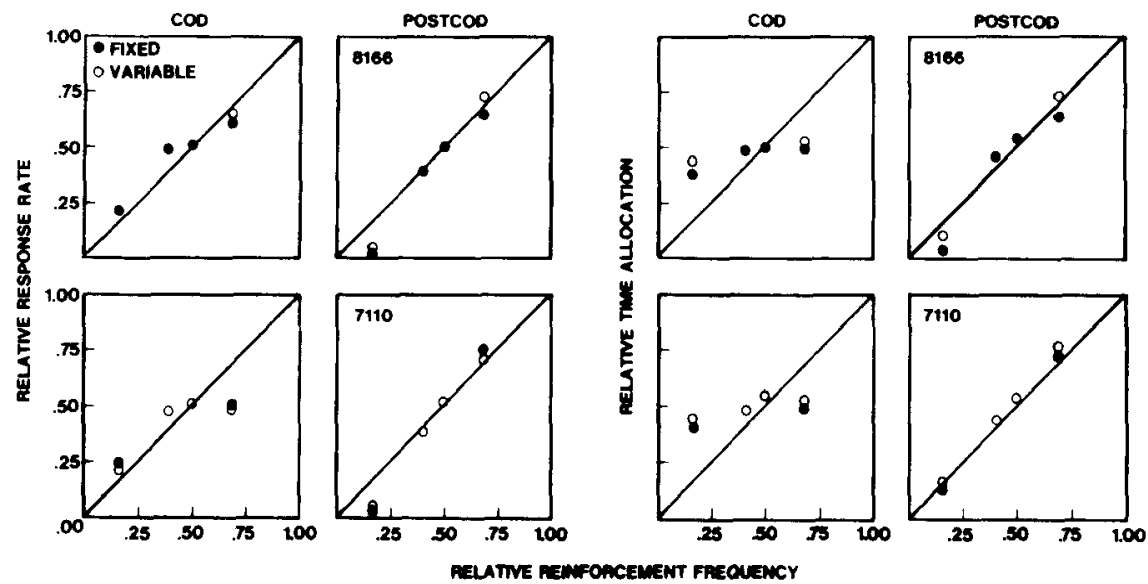

Figure 7. Relative response rate and time allocation measures for the COD and post-COD periods for Subjects 8166 and 7110 in Experiment 3. Open and closed circles indicate whether the COD was of fixed (closed) or variable (open) duration. 
average ICT was shorter when a COD of variable duration was used instead of a COD of fixed duration. This was the case not only when the duration of the CODs was parametrically varied (as in Experiment 2), but also when the relative frequency of reinforcement was systematically manipulated (as in Experiment 3 ). Second, it was consistently found that the differences between COD and post-COD response rates were greatly reduced when a COD of variable, rather than fixed, duration was used. Other researchers (Guilkey et al., 1975; Pliskoff et al., 1978; White, 1979) have also failed to obtain a substantial increase in response rates immediately after the $\mathrm{CO}$ response when they used a FR changeover requirement instead of a COD of fixed duration. The results of their experiments together with the present findings indicate that elevated response rates immediately after the $\mathrm{CO}$ response may occur only when a COD of fixed duration is used. The experimental contingencies arranged at the time of the $\mathrm{CO}$ response therefore determine to a great extent the specific quantitative characteristics of the behavior observed at that instance.

The COD of fixed duration can be best described as a subject-controlled stimulus change superimposed upon a conc VI VI baseline schedule of reinforcement having a conditioned reinforcing function for the behavior preceding it and a discriminative function for responding following the stimulus change. These two functions are illustrated by the results of this and previous experiments.

The duration of the ICTs between the components of a concurrent schedule increases as the duration of the COD is increased. However, the duration of the ICT increases less when a COD of variable duration is used instead of one of fixed duration. This indicates that pigeons are more likely to initiate a COD of variable duration than they are to initiate a COD of fixed duration. Two factors, both inherent in the way in which the COD is arranged in concurrent schedules, combine to produce this phenomenon. First, the probability of reinforcement availability in one component of a concurrent schedule increases as more time is spent responding in the other component of the schedule. The probability of reinforcement for the first response after the expiration of a COD is relatively high, as compared with the responses immediately preceding it, given an ICT of appropriate duration. The COD itself is also a period of time during which reinforcement is definitely not available. It therefore functions, in effect, as a delay period to the next opportunity for reinforcement. Evidence is available (Cicerone, 1976) to support the notion that pigeons prefer variable delays to reinforcement over fixed delays, a finding analogous to the fact that our subjects were more likely to initiate a COD of variable duration than one of fixed duration. It has similarly been shown in research on concurrent-chain schedules of reinforcement that pigeons prefer variable-interval schedules over fixedinterval schedules of reinforcement, indicating that the choice behavior of pigeons is controlled by temporal variables (Davison, 1969, 1972; Herrnstein, 1964).

The effects of CODs of fixed or variable duration are also quantitatively different when response rates during the COD are compared with post-COD response rates. Evidently, a COD can also function as a response-initiated discriminative stimulus controlling the characteristics of the behavior occurring in its presence. Pierce, Hanford, and Zimmerman (1972) have previously shown such control in simple delay of reinforcement studies with rats.

In summary, it can be said that the role of the COD in conc VI VI schedules is not necessarily as straightforward as has been assumed (Catania, 1966). These studies have shown that the COD affects more molecular aspects of the choice behavior of pigeons, while regulating the same at a molar level.

\section{REFERENCES}

Allison, T. S., \& LLOYD, K. E. Concurrent schedules of reinforcement: Effects of gradual and abrupt increases in changeover delay. Journal of the Experimental Analysis of Behavior, 1971, 16, 67-73.

Bourland, G., \& Miller, J. T. Role of discriminative stimuli in concurrent performances: Duration of changeover delay. Psychological Record, 1978, 28, 263-271.

Brownstein, A. J., \& Pliskoff, S. S. Some effects of relative reinforcement rate and changeover delay in response-independent concurrent schedules of reinforcement. Journal of Experimental Analysis of Behavior, 1968, 11, 683-688.

Catania, A. C. Concurrent operants. In W. K. Honig (Ed.), Operant behavior: Areas of research and application. Englewood Cliffs, N.J: Prentice-Hall, 1966.

Catania, A. C., \& Reynolds, G. S. A quantitative analysis of the responding maintained by interval schedules of reinforcement. Journal of the Experimental Analysis of Behavior, 1968, 11, 327-383.

Cicerone, R. A. Preference for mixed versus constant delay of reinforcement. Journal of the Experimental Analysis of Behavior, 1976, 25, 257-261.

Davison, M. C. Preference for mixed-interval versus fixed-interval schedules. Journal of the Experimental Analysis of Behavior, $1969,12,247-252$.

Davison, M. C. Preference for mixed-interval versus fixed-interval schedules: Number of component intervals. Journal of the Experimental Analysis of Behavior, 1972, 17, 169-176.

DEVilliers, $\mathbf{P}$. Choice in concurrent schedules and a quantitative formulation of the law of effect. In W. K. Honig \& J. E. R. Staddon (Eds.), Handbook of operant behavior. Englewood Cliffs, N.J: Prentice-Hall, 1977.

Findley, J. D. Preference and switching under concurrent scheduling. Journal of the Experimental Analysis of Behavior, 1958, 1, 123-144.

Guilkey, M., Shull, R. L., \& Brownstein, A. Response rate invariance in concurrent schedules: Effects of different changeover contingencies. Journal of the Experimental Analysis of Behavior, 1975, 24, 43-52.

HERRNSTEIN, R. J. Relative and absolute strength of response as a function of the frequency of reinforcement. Journal of the Experimental Analysis of Behavior, 1961, 4, 267-272.

HerRnstein, R. J. Aperiodicity as a factor in choice. Journal of the Experimental Analysis of Behavior, 1964, 7, 179-182. 
KILLEEN, P. A yoked-chamber comparison of concurrent and multiple schedules. Journal of the Experimental Analysis of Behavior, 1972, 18, 13-22.

Pierce, C. H., Hanford, P. V., \& Zimmerman, J. Effects of different delay of reinforcement procedures on variable-interval responding. Journal of the Experimental Analysis of Behavior, 1972, 18, 141-146.

PuiskofF, S. S. Effects of symmetrical and asymmetrical changeover delays on concurrent performances. Journal of the Experimental Analysis of Behavior, 1971, 16, 249-256.

Pliskoff, S. S., Cicerone, R., \& Nelson, T. D. Local response rate constancy on concurrent variable-interval schedules of reinforcement. Journal of the Experimental Analysis of Behavior, $1978,29,431-446$.

Shull, R. L., \& Pliskoff, S. S. Changeover delay and concurrent schedules: Some effects on relative performance measures. Journal of the Experimental Analysis of Behavior, 1967, 10, $517-527$.
Silberberg, A., \& Fantino, E. Choice, rate of reinforcement and the changeover delay. Journal of the Experimental Analysis of Behavior, 1970, 13, 187-197.

Snapper, A. G., van HaAren, F., \& Inglis, G. B. The SKED software system: SUPERSKED papertape version. Kalamazoo, Mich: The SKED Users Group, 1978.

Stubbs, D. A., \& Pliskoff, S. S. Concurrent responding with fixed relative rate of reinforcement. Journal of the Experimental A nalysis of Behavior, 1969, 12, 887-895.

Todorov, J. C. Concurrent performances: Effects of punishment contingencies on the switching response. Journal of the Experimental A nalysis of Behavior, 1971, 16, 51-62.

White, J. M. Changeover ratio effects on concurrent variableinterval performance. Journal of the Experimental Analysis of Behavior, 1979, 31, 239-252.

(Received for publication September 21, 1980; revision accepted February 1, 1981.) 